\title{
Extremely skewed X-chromosome inactivation is increased in pre-eclampsia
}

\author{
Elif Uz • Ismail Dolen • Atakan R. Al • Tayfun Ozcelik
}

Received: 17 February 2006 / Accepted: 11 October 2006 / Published online: 7 November 2006

(C) Springer-Verlag 2006

\begin{abstract}
Pre-eclampsia is a disorder that affects approximately $5 \%$ of pregnancies. We tested the hypothesis that skewed X-chromosome inactivation (XCI) could be involved in the pathogenesis of preeclampsia. Peripheral blood DNA was obtained from 67 pre-eclampsia patients and 130 control women. Androgen receptor (AR) was analyzed by the HpaII/ polymerase chain reaction assay to assess XCI patterns in DNA extracted from peripheral-blood cells. In addition, buccal cells were obtained from seven patients, and the analysis repeated. Extremely skewed XCI was observed in 10 of 46 informative patients $(21.74 \%)$, and in 2 of 86 informative controls $(2.33 \%, P=0.0005$; $\chi^{2}$ test). Our findings support a role for the X-chromosome in the pathogenesis of pre-eclampsia in a subgroup of patients.
\end{abstract}

\section{Introduction}

Pre-eclampsia is a pregnancy-specific syndrome of unknown etiology. It is the leading cause of maternal and perinatal mortality, characterized by increased

Electronic supplementary material Supplementary material is available in the online version of this article at http://dx.doi.org/ 10.1007/s00439-006-0281-3 and is accessible for authorized users.

E. Uz $\cdot$ T. Ozcelik $(\bowtie)$

Department of Molecular Biology and Genetics, Bilkent University, Bilkent, Ankara 06800, Turkey

e-mail: tozcelik@fen.bilkent.edu.tr

I. Dolen · A. R. Al

Etlik Maternity and Women's Health Teaching Hospital, Ministry of Health, 06100 Ankara, Turkey blood pressure and proteinuria (Roberts and Cooper 2001; Broughton Pipkin 2001). The disease occurs only in the presence of a placenta and resolves with the removal of the placenta. Studies that aim to identify susceptibility loci with significant linkage to familial cases of pre-eclampsia (OMIM 189800) resulted in the identification of four chromosome regions: $2 \mathrm{p} 13$ (Iceland) (Arngrimsson et al. 1999), 2p25 and 9p13 (Finland) (Laivuori et al. 2003), and 10q22 (The Netherlands) (Lachmeijer et al. 2001; Oudejans et al. 2004). The Dutch pre-eclampsia locus shows maternal segregation, and recently STOX1 (storkhead box 1; also called C10orf24), was identified as a candidate gene for this locus (van Dijk et al. 2005).

Maternal endothelial dysfunction and failure of the tolerance system as evidenced by Th- 1 type immunity are early pathophysiological modifications in preeclampsia (Saito and Sakai 2003). Failure of the tolerance system is associated with autoimmune diseases. A negative selection system against potentially self-reactive T-cells in the thymic medulla and cortex-medulla junction is critically important in establishing $\mathrm{T}$-cell tolerance. The negative selection process is mediated primarily by the dendritic cells, which participate in antigen presentation (Speiser et al. 1989; Laufer et al. 1996). Lack of exposure to self-antigens in the thymus and the presence of autoreactive T-cells have been shown to increase the risk of autoimmunity (Klein et al. 2000).

It was hypothesized that disturbed X-chromosome inactivation (XCI) could be a mechanism whereby lack of exposure to self-antigens may occur in females (Kast 1977; Stewart 1998). X-inactivation is an epigenetic modification in females that results in the transcriptional inactivation of one of the pair of X-chromosomes at 
random (Lyon 1961). Normal females are thus mosaics of two cell populations. Four recently published studies, one by a Japanese group on primary ovarian failure (Sato et al. 2004), one by us on scleroderma (Ozbalkan et al. 2005), and two on autoimmune thyroid diseases (Brix et al. 2005; Ozcelik et al. 2006), raised the possibility that skewed XCI could play an important role in the pathogenesis of autoimmune diseases. Since the disease may have an autoimmune component, we hypothesized that skewed XCI could be involved in the pathogenesis of pre-eclampsia as well.

We observed that the number of women with extreme skewing of XCI is significantly higher in the pre-eclampsia group than in healthy control women with no history of pre-eclampsia, autoimmune diseases or cancer. The cause of skewed XCI mosaicism in autoimmune diseases and pre-eclampsia is not yet known. Possible mechanisms include skewing of XCI as cause of the disease, or alternatively the cause of pre-eclampsia could also be the cause of the skewing.

\section{Materials and methods}

\section{Patients}

Sixty-seven Caucasian women diagnosed with preeclampsia, and 130 apparently healthy Caucasian female controls were genotyped to determine whether women with pre-eclampsia have a greater frequency of extremely skewed XCI than control subjects. The ethics review board of the participating institutions approved study protocol. Pregnancy history, age, and disease information accompanied by informed consent was obtained from all subjects. In the control group $(124 / 130)$ women gave birth to at least one child, and none had a history of pregnancy loss, autoimmune disease or cancer. The birth registry at the Etlik Maternity and Women's Health Teaching Hospital in Ankara was used to contact the pre-eclamptic cases. All women in the patient group had singleton deliveries. The mean ages were $29.8 \pm 5.7$ years (mean $\pm \mathrm{SD}$; range $=21$ 42 years old) for the cases, and $31.6 \pm 5.6$ (range $=21-$ 47 years old) for the controls.

Pre-eclampsia was defined as the development of hypertension plus proteinuria within 7 days of each other after the twentieth week of gestation in women with no proteinuria at baseline. Hypertension and severe hypertension were defined as diastolic blood pressures of at least 90 and $110 \mathrm{~mm} \mathrm{Hg}$, respectively, occurring on at least two occasions, 4-168 h apart. Urinary protein excretion of $>300 \mathrm{mg}$ in $24 \mathrm{~h}$ was indicative of proteinuria. Pre-eclampsia was considered severe in the presence of severe hypertension or severe proteinuria, HELLP syndrome (haemolysis, elevated liver enzymes, low platelets), or eclampsia. Those subjects with a previous history of chronic hypertension, renal disease or diabetes mellitus were excluded.

\section{$\mathrm{X}$-chromosome inactivation analysis}

DNA was extracted from $10 \mathrm{ml}$ venous blood samples with NucleoSpin Blood kit (Macherey-Nagel, Düren, Germany) according to the manufacturer's protocol. After ethanol precipitation, DNA was dissolved in distilled water and stored at $4^{\circ} \mathrm{C}$.

Genotyping of a highly polymorphic CAG repeat in the androgen-receptor (AR) gene was performed to assess the XCI patterns (Allen et al. 1992). Patients with $\geq 90 \%$ representation of one allele were classified as extremely skewed XCI. The DNA was divided into two identical aliquots, one of which was incubated overnight at $37^{\circ} \mathrm{C}$ with methylation-sensitive restriction enzyme HpaII (MBI Fermentas, Vilnius, Lithuania) for the digestion of unmethylated (or active) alleles. A second restriction enzyme, RsaI (MBI Fermentas, Vilnius, Lithuania), which recognizes a four base pair sequence not present in the amplified region of the $A R$ locus was also included in the reaction to facilitate the HpaII digestion process. The other aliquot of the DNA was digested with $R s a \mathrm{I}$ alone as a control. Male DNA with cytogenetically verified 46XY karyotype was used as a control for incomplete digestion.

After restriction enzyme digest, residual DNA was amplified by using the primers 5'-GTC CAA GAC CTA CCG AGG AG-3' and 5' -CCA GGA CCA GGT AGC CTG TG-3'. Amplicons were labeled by including a radioactive nucleotide $\left(\alpha-\left[{ }^{33} \mathrm{P}\right]-\mathrm{dCTP}\right)$ (NEN, Perkin Elmer Life Sciences, Boston, Massachusetts) in the polymerase chain reaction (PCR). PCR products were separated on $8 \%$ denaturing 29:1 acrylamide/bisacrylamide gel for $5 \mathrm{~h}$ at $60 \mathrm{~W}$. Gels were dried and autoradiographed on Medicalfilm CP-BU (Agfa, AgfaGevaert AG, Belgium). Densitometric analysis of the alleles was performed at least twice for each sample using the appropriate software (MultiAnalyst version 1.1; Bio-Rad, Hercules, California).

In addition, cold PCR followed by electrophoretic separation of the alleles in $4 \%$ MetaPhor agarose (FMC BioProducts, Rockland, Maine) for $4 \mathrm{~h} 30 \mathrm{~min}$ at $80 \mathrm{~V}$ was carried out. Since the number of cycles could be critically important for the outcome of densitometric analyses, samples were subjected to 25 and also 30 cycles of amplification during the hot and the cold PCR. Products were visualized by ethidium bromide 
staining, and densitometric analysis of the alleles was performed at least twice for each sample using the MultiAnalyst version 1.1software. A corrected ratio $(\mathrm{CrR})$ was calculated by dividing the ratio of the predigested sample (upper/lower allele) by the ratio of the non-predigested sample for normalization of the ratios that were obtained from the densitometric analyses. The use of CrR compensates for preferential amplification of the shorter allele when the number of PCR cycles increases (Delforge et al. 1995). A skewed population is defined as a cell population with greater than $80 \%$ expression of one of the $A R$ alleles. This corresponds to $\mathrm{CrR}$ values of $<0.33$ or $>3$.

\section{Statistical methods}

The results from control and test groups were compared by the Fisher's exact test.

\section{Results}

XCI status was found to be informative in $69 \%$ of the cases (46/67) and $66 \%$ of the controls (86/130). Only those individuals whose alleles resolve adequately for densitometric analysis were included in the study. Extremely skewed XCI was present in ten $(21.74 \%)$ cases and two $(2.33 \%)$ controls $(P=0.0005)$. It is well established that extremely skewed $\mathrm{XCI}$ is a rare event in a diverse group of control females (Busque et al. 1996; Naumova et al. 1996; Sharp et al. 2000; AmosLandgraf et al. 2006). When XCI values between 80 and $89 \%$ were also considered, skewed XCI was observed in 16 of the $46(34.78 \%)$ informative cases, and 8 of the $86(9.30 \%)$ controls $(P=0.0006)$ (Table 1$)$. DNA from buccal cells was analyzed in seven patients with various degrees of skewing. They were chosen randomly to assess whether the results from blood, a mesodermal tissue, is comparable to other tissue types such as buccal cells, which have an ectodermal origin. Similar XCI patterns were observed (Table 2). Since it would be of interest to identify differences in the pregnancy details between those of women with extreme skewing, and women with normal $\mathrm{X}$-inactivation, we obtained clinical characteristics of the pre-eclampsia patients informative for XCI status, and the controls (Supplemental Tables 1,2). Although the numbers are too small to reach a conclusion, it is interesting that recurrent spontaneous abortions is three times more common in women with extreme skewing (3/10) than in women with random patterns of XCI (3/30) (Supplemental Table 3). It is well established that the frequency of skewed XCI is increased in recurrent
Table 1 Proportion of the patients and controls with skewed $\mathrm{XCI}$

\begin{tabular}{llc}
\hline $\begin{array}{l}\text { Degree of } \\
\text { skewing } \\
(\%)\end{array}$ & $\begin{array}{l}\text { No. }(\%) \text { observed } \\
\text { with skewing }\end{array}$ & \\
\cline { 2 - 3 } & $\begin{array}{l}\text { Pre-eclampsia } \\
\text { patients } \\
(n=46)\end{array}$ & $\begin{array}{l}\text { Control } \\
\text { females } \\
(n=86)\end{array}$ \\
\hline $90+$ & $10(21.74)$ & $2(2.33)$ \\
$80-89$ & $6(13.04)$ & $6(6.98)$ \\
$70-79$ & $6(13.04)$ & $15(17.44)$ \\
$60-69$ & $13(28.26)$ & $20(23.26)$ \\
$50-59$ & $11(23.91)$ & $43(50.00)$ \\
\hline
\end{tabular}

For comparison by $\chi^{2}, P=0.0006$ (>80\% skewing); $P=0.0005$ ( $\geq 90 \%$ skewing)

Table 2 X-chromosome inactivation patterns in blood and buccal mucosa specimens

\begin{tabular}{llllllll}
\hline Sample & $04-176$ & $04-182$ & $04-190$ & $04-298$ & $04-192$ & $04-284$ & $04-289$ \\
\hline Blood & $91: 90$ & $93: 70$ & $90: 10$ & $98: 20$ & $83: 17$ & $71: 29$ & $70: 30$ \\
Buccal & $90: 10$ & $90: 10$ & $90: 10$ & $100: 0$ & $80: 20$ & $69: 31$ & $66: 34$
\end{tabular}

spontaneous abortions (Lanasa et al. 1999; Sangha et al. 1999; Bagislar et al. 2006). Interestingly, a common genetic background for pre-eclampsia and recurrent spontaneous abortions has been questioned in the medical literature (Christiansen et al. 1990).

\section{Discussion}

We observed skewed XCI patterns in peripheral-blood mononuclear cells of a significant proportion (35\%) of females with pre-eclampsia. Approximately $9 \%$ of female control subjects demonstrated skewed XCI patterns $\geq 80: 20$. The effect is also pronounced at patterns of XCI $\geq 90: 10$; nearly a quarter of pre-eclampsia patients showed such skewing, compared with only $2 \%$ of control subjects. Although skewed XCI patterns $\geq 80: 20$ could be as high as $19.5 \%$ (Amos-Landgraf et al. 2006) or $21.6 \%$ (Naumova et al. 1996) in phenotypically normal females, skewing in the range of $\geq 90: 10$ or $\geq 95: 5$ is quite rare with only 3.6 and $1.7 \%$ of the population, respectively (Amos-Landgraf et al. 2006). With respect to the relatively low percentage of controls in the $\geq 80: 20$ range in our study, this result may be a reflection of the pregnancy histories. An overwhelming majority (124/130) had experienced a normal pregnancy period with healthy deliveries.

Clinical manifestation of $\mathrm{X}$-linked disorders in females could be influenced as a consequence of disturbances in the XCI process (Lyon 2002). High frequency of skewed XCI has also been observed in 
recurrent spontaneous abortions (Lanasa et al. 1999; Sangha et al. 1999), X-linked mental retardation (Plenge et al. 2002), breast and ovarian cancers (Kristiansen et al. 2002), and in mothers of homosexual men (Bocklandt et al. 2006). In addition, it has been hypothesized that skewed XCI could be a factor that influences female predisposition to autoimmunity: recently skewed XCI has been reported in three autoimmune disorders, scleroderma (Ozbalkan et al. 2005), autoimmune thyroid diseases (Brix et al. 2005; Ozcelik et al. 2006), and premature ovarian failure (Sato et al 2004).

Skewed XCI could be the result of a bias in the initial choice of which X-chromosome is inactivated (primary cause), or selection against cells in which a given $\mathrm{X}$-chromosome has been inactivated (secondary cause) [for review see Puck and Willard 1998; Brown 1999]. At present, we do not know the nature of the relationship between XCI patterns and pre-eclampsia; except that aging (a secondary cause) is highly unlikely to be involved because of the relatively young ages of the patients (mean age of diagnosis at $29.8 \pm 5.7$ years for all the patients, $30.3 \pm 6.2$ years for patients with skewed XCI, and $29.4 \pm 5.5$ years for patients with random XCI) (Fig. 1). However, two possibilities could be considered: The cause of pre-eclampsia could also be the cause of the skewing, or the skewing of XCI could be the cause of pre-eclampsia. If the autoimmune reaction is the cause of the secondary selection, the disease would cause the skewing. Alternatively, if the disease is at least partially caused by an X-chromosome gene, the disease allele could increase or decrease the fitness of cells inactivating the wild type or mutant allele of this gene, leading to secondary selection for immune cells inactivating one or both X-chromosomes. This would mean that the $\mathrm{X}$-linked gene causes both the disease and the skewing. Since both, pre-eclampsia and skewed XCI may be heritable traits, the women with preeclampsia and skewed XCI may share the same mutation(s) in one or more X-linked genes. This implies that it would be particularly important to establish if any of the women who are included in the study were related. However, they were neither related, nor were they from the same geographical location.

Skewed XCI patterns are now demonstrated in a significant proportion of a subgroup of pre-eclampsia patients. Therefore, disturbed XCI mosaicism could be considered as a contributing factor to disease pathogenesis. Further studies, such as haplotype analysis of $\mathrm{X}$-linked markers in mother-child pairs of pre-eclampsia patients, and a search for X-chromosomal aberrations in pre-eclampsia patients by microarray analysis (Larrabee et al. 2004), could be critically important in understanding the genetic etiology.
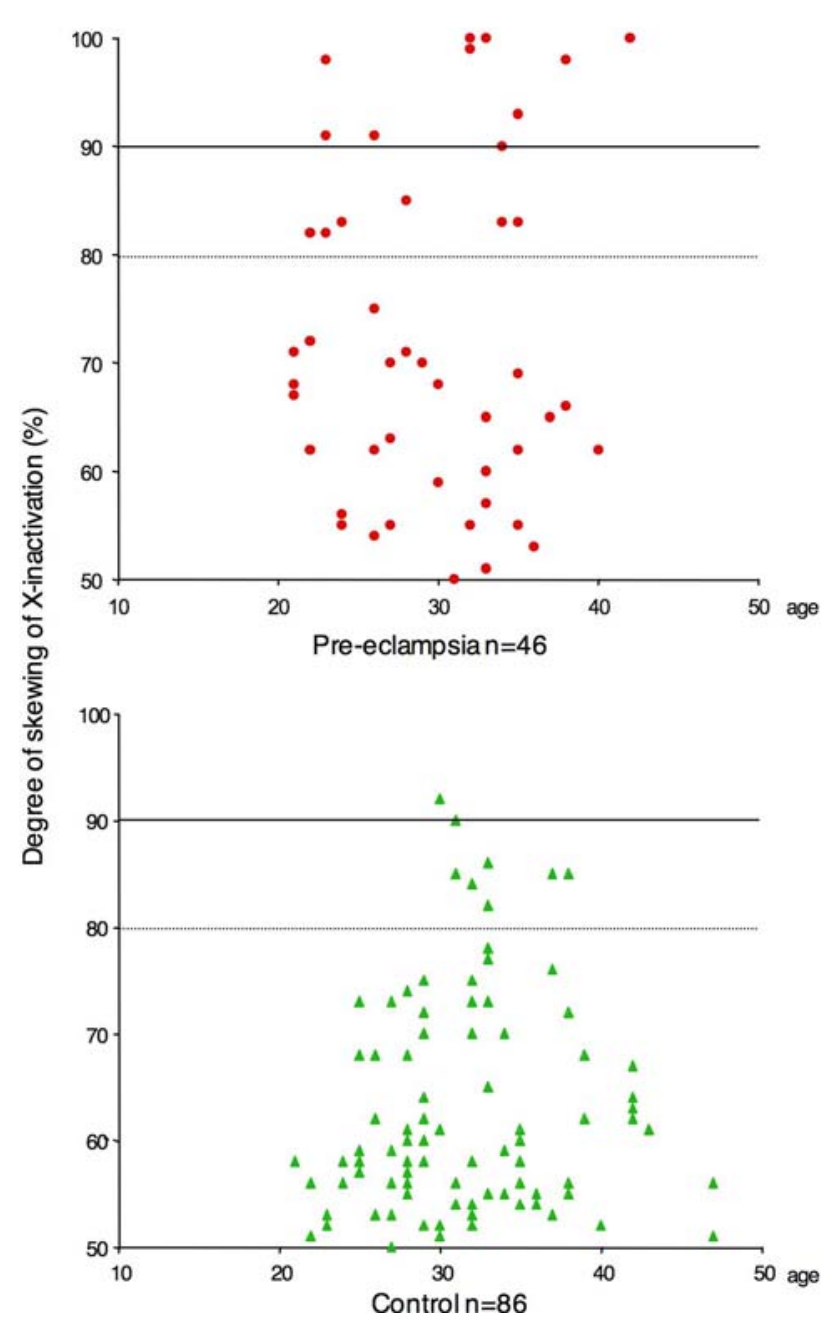

Fig. 1 Distribution of X-chromosome inactivation patterns according to age in pre-eclampsia patients and control subjects

Acknowledgments We would like to thank Margaret Sands and Iclal Ozcelik for critical reading of the manuscript, and Sevgi Bagislar for technical help. Supported by grants from the Scientific and Technical Research Council of Turkey-TUBITAK-SBAG 3334, International Centre for Genetic Engineering and Biotechnology-ICGEB-CRP/TUR04-01, and Bilkent University Research Fund (to Dr. Ozcelik).

\section{References}

Allen RC, Zoghbi HY, Moseley AB, Rosenblatt HM, Belmont JW (1992) Methylation of HpaII and HhaI sites near the polymorphic CAG repeat in the human androgen-receptor gene correlates with X-chromosome inactivation. Am J Hum Genet 51:1229-1239

Amos-Landgraf JM, Cottle A, Plenge RM, Friez M, Schwartz CE, Longshore J, Willard HF (2006) X chromosome inactivation patterns of 1,005 phenotypically unaffected females. Am J Hum Genet 79:493-499

Arngrimsson R, Sigurardttir S, Frigge ML, Bjarnadttir RI, Jonsson T, Stefansson H, Baldursdottir A, Einarsdottir AS, Palsson B, Snorradottir S, Lachmeijer AM, Nicolae D, 
Kong A, Bragason BT, Gulcher JR, Geirsson RT, Stefansson K (1999) A genome-wide scan reveals a maternal susceptibility locus for preeclampsia on chromosome $2 \mathrm{p} 13$. Hum Mol Gen 8:1799-1805

Bagislar S, Ustuner I, Cengiz B, Soylemez F, Akyerli CB, Ceylaner S, Ceylaner G, Acar A, Ozcelik T (2006) Extremely skewed $\mathrm{X}$-chromosome inactivation patterns in women with recurrent spontaneous abortion. Aust N Z J Obstet Gynaecol 46:384-387

Bocklandt S, Horvath S, Vilain E, Hamer DH (2006) Extreme skewing of $\mathrm{X}$ chromosome inactivation in mothers of homosexual men. Hum Genet 118:691-694

Brix TH, Knudsen GPS, Kristiansen M, Kyvik KO, Ørstavik KH, Hegedüs L (2005) High frequency of skewed X chromosome inactivation in females with autoimmune thyroid disease: a possible explanation for the female predisposition to thyroid autoimmunity. J Clin Endocrinol Metab 90:5949-5953

Broughton Pipkin F (2001) Risk factors for preeclampsia. New Engl J Med 344:925-926

Brown CJ (1999) Skewed X-chromosome inactivation: cause or consequence? J Natl Cancer Inst 91:304-305

Busque L, Mio R, Mattioli J, Brais E, Brais N, Lalonde Y, Maragh M, Gilliland DG (1996) Non-random X-inactivation patterns in normal females: lyonization ratios vary with age. Blood 88:59-65

Christiansen OB, Mathiesen O, Grunnet N, Jersild C, Lauritsen JG (1990) Is there a common genetic background for pre-eclampsia and recurrent spontaneous abortions? Lancet 335:361-362

Delforge M, Demuynck H, Vandenberghe P, Verhoef G, Zachee P, Van Duppen V, Marijnen P, Van den Berghe H, Boogaerts M (1995) Polyclonal primitive hematopoietic progenitors can be detected in mobilized peripheral blood from patients with high-risk myelodysplastic syndromes. Blood 86:3660-3667

Kast RE (1977) Predominance of autoimmune and rheumatic diseases in females. J Rheumatol 4:288-292

Klein L, Klugmann M, Nave KA, Tuohy VK, Kyewski B (2000) Shaping of the autoreactive T-cell repertoire by a splice variant of self protein expressed in thymic epithelial cells. Nat Med 6:56-61

Kristiansen M, Langerod A, Knudsen GP, Weber BL, BorresenDale AL, Ostravik KH (2002) High frequency of skewed X inactivation in young breast cancer patients. J Med Genet 39:30-33

Lachmeijer AM, Arngrimsson R, Bastiaans EJ, Frigge ML, Pals G, Sigurdardottir S, Stefansson H, Palsson B, Nicolae D, Kong A, Aarnoudse JG, Gulcher JR, Dekker GA, ten Kate LP, Stefansson K (2001) A genome-wide scan for preeclampsia in the Netherlands. Eur J Hum Genet 9:758-764

Laivuori H, Lahermo P, Ollikainen V, Widen E, Haiva-Mallinen L, Sundstrom H, Laitinen T, Kaaja R, Ylikorkala O, Kere J (2003) Susceptibility loci for preeclampsia on chromosome 2p25 and 9p13 in Finnish families. Am J Hum Genet 72:168-177

Lanasa MC, Hogge WA, Kubick C, Blancato J, Hoffman EP (1999) Highly skewed X-chromosome inactivation is associated with idiopathic recurrent spontaneous abortion. Am J Hum Genet 65:252-254

Larrabee PB, Johnson KL, Pestova E, Lucas M, Wilber K, LeShane ES, Tantravahi U, Cowan JM, Bianchi DW (2004) Microarray analysis of cell-free fetal DNA in amniotic fluid: a prenatal molecular karyotype. Am J Hum Genet 75:485-491
Laufer TM, DeKoning J, Markowitz JS, Lo D, Glimcher LH (1996) Unopposed positive selection and autoreactivity in mice expressing class II MHC only on thymic cortex. Nature 383:81-85

Lyon MF (1961) Gene action in the X-chromosome of the mouse (Mus musculus). Nature 190:372-373

Lyon MF (2002) X-chromosome inactivation and human genetic disease. Acta Paediatr Suppl 91:107-112

Naumova AK, Plenge RM, Bird LM, Leppert M, Morgan K, Willard HF, Sapienza C (1996) Heritability of X chromosomeinactivation phenotype in a large family. Am J Hum Genet 58:1111-1119

Oudejans CB, Mulders J, Lachmeijer AM, van Dijk M, Konst AA, Westerman BA, van Wijk IJ, Leegwater PA, Kato HD, Matsuda T, Wake N, Dekker GA, Pals G, ten Kate LP, Blankenstein MA (2004) The parent-of-origin effect of 10q22 in preeclamptic females coincides with two regions clustered for genes with down regulated expression in androgenetic placentas. Mol Hum Reprod 8:589-598

Ozbalkan Z, Bagislar S, Kiraz S, Akyerli CB, Ozer HT, Yavuz S, Birlik AM, Calguneri M, Ozcelik T (2005) Skewed X chromosome inactivation in blood cells of women with scleroderma. Arthritis Rheum 52:1564-1570

Ozcelik T, Uz E, Bagislar S, Mustafa CA, Gursoy A, Akarsu N, Toruner G, Kamel N, Gullu S (2006) Evidence from autoimmune thyroiditis of skewed $\mathrm{X}$-chromosome inactivation in female predisposition to autoimmunity. Eur J Hum Genet 14:791-797

Plenge RM, Stevenson RA, Lubs HA, Schwartz CE, Willard HF (2002) Skewed X-chromosome inactivation is a common feature of X-linked mental retardation disorders. Am J Hum Genet 71:168-173

Puck J, Willard H (1998) X-inactivation in females with X-linked disease. N Engl J Med 338:325-328

Roberts JM, Cooper DW (2001) Pathogenesis and genetics of pre-eclampsia. Lancet 357:53-56

Sangha KK, Stephenson MD, Brown CJ, Robinson WP (1999) Extremely skewed X-chromosome inactivation is increased in women with recurrent spontaneous abortion. Am J Hum Genet 65:913-917

Saito S, Sakai M (2003) Th1/Th2 balance in preeclampsia. J Reprod Immunol 59:161-173

Sato K, Uehara S, Hashiyada M, Nabeshima H, Sugawara J, Terada Y, Yaegashi N, Okamura K (2004) Genetic significance of skewed $\mathrm{X}$-chromosome inactivation in premature ovarian failure. Am J Med Genet 130A:240-244

Sharp A, Robinson D, Jacobs P (2000) Age- and tissue-specific variation of $\mathrm{X}$ chromosome inactivation ratios in normal women. Hum Genet 107:343-349

Speiser DE, Lees RK, Hengartner H, Zinkernagel RM, MacDonald HR (1989) Positive and negative selection of T cell receptor $\mathrm{V}$ beta domains controlled by distinct cell populations in the thymus. J Exp Med 170:2165-2170

Stewart JJ (1998) The female X-inactivation mosaic in systemic lupus erythematosus. Immunol Today 19:352-357

van Dijk M, Mulders J, Poutsma A, Konst AA, Lachmeijer AM, Dekker GA, Blankenstein MA, Oudejans CB (2005) Maternal segregation of the Dutch preeclampsia locus at $10 \mathrm{q} 22$ with a new member of the winged helix gene family. Nat Genet 37:514-519 